\title{
An evidence map of actigraphy studies exploring longitudinal associations between rest-activity rhythms and course and outcome of bipolar disorders
}

\author{
Jan Scott ${ }^{1,2,3}$, Francesc Colom ${ }^{4,5}$, Allan Young ${ }^{2,8}$, Frank Bellivier ${ }^{3,6,7}$ and Bruno Etain $3,6,7^{*}$ (D)
}

\begin{abstract}
Background: Evidence mapping is a structured approach used to synthesize the state-of-the-art in an emerging field of research when systematic reviews or meta-analyses are deemed inappropriate. We employed this strategy to summarise knowledge regarding longitudinal ecological monitoring of rest-activity rhythms (RAR) and disease modifiers, course of illness, treatment response or outcome in bipolar disorders (BD).

Structure: We had two key aims: (1) to determine the number and type of actigraphy studies of in BD that explored data regarding: outcome over time (e.g. relapse/recurrence according to polarity, or recovery/remission), treatment response or illness trajectories and (2) to examine the range of actigraphy metrics that can be used to estimate disruptions of RAR and describe which individual circadian rhythm or sleep-wake cycle parameters are most consistently associated with outcome over time in BD. The mapping process incorporated four steps: clarifying the project focus, describing boundaries and 'coordinates' for mapping, searching the literature and producing a brief synopsis with summary charts of the key outputs. Twenty-seven independent studies (reported in 29 publications) were eligible for inclusion in the map. Most were small-scale, with the median sample size being 15 per study and median duration of actigraphy being about 7 days (range 1-210). Interestingly, 17 studies comprised wholly or partly of inpatients (63\%). The available evidence indicated that a discrete number of RAR metrics are more consistently associated with transition between different phases of BD and/or may be predictive of longitudinal course of illness or treatment response. The metrics that show the most frequent associations represent markers of the amount, timing, or variability of RAR rather than the sleep quality metrics that are frequently targeted in contemporary studies of BD.

Conclusions: Despite 50 years of research, use of actigraphy to assess RAR in longitudinal studies and examination of these metrics and treatment response, course and outcome of $\mathrm{BD}$ is under-investigated. This is in marked contrast to the extensive literature on case-control or cross-sectional studies of actigraphy, especially typical sleep analysis metrics in BD. However, given the encouraging findings on putative RAR markers, we recommend increased study of putative circadian phenotypes of BD.
\end{abstract}

Keywords: Evidence map, Actigraphy, Longitudinal, Bipolar, Response, Course, Modifiers, Lithium, Phenotype, Domains

\footnotetext{
${ }^{*}$ Correspondence: bruno.etain@inserm.fr

${ }^{3}$ Université Paris Diderot, Sorbonne Paris Cité, UMR-S 1144, 75013 Paris, France

Full list of author information is available at the end of the article
}

\section{Introduction}

In the 2017 update on the global burden of disease demonstrates that, the four most burdensome non-communicable conditions (in terms of DALYs: disability adjusted 
life years) are: cardiovascular disease (CVD), cancers, musculoskeletal conditions, and mental disorders (GBD 2017; Whiteford et al. 2013). In individuals aged 15-49, mental disorders in general, and mood disorders specifically, are regarded as the most burdensome conditions worldwide. In the last 3 to 4 decades, considerable progress has been made in the management of CVD and cancer through precision medicine. The application of precision medicine is in its infancy in psychiatry, but funding initiatives (such as the European H2020 platform) are supporting studies of personalized diagnostics and therapeutics across a range of mental conditions including bipolar disorders (BD) (Schumann et al. 2014). Like precision approaches to other chronic disorders, these studies have largely focused on more quantifiable metrics (such as 'omics' and brain scanning) as an attempt to increase the biological validity of observed symptoms (Frey et al. 2013; Hellwig and Domschke 2019; MacDonald et al. 2019). This strategy also reflects the proposals described in the RDOC (research domain criteria) paradigm that identifies key domains and analytic units for translational research (Cuthbert and Insel 2013; Insel 2014). Although personalized diagnostics for $\mathrm{BD}$ are likely to remain a long-term aspiration, there is emerging evidence that multi-platform, integrated science approaches could offer a pathway for stratifying individuals with $\mathrm{BD}$ to improve outcome prediction, namely treatment response, relapse and recurrence, and individual illness trajectories (Scott et al. 2018). However, as these efforts progress, there is a need to extent the search for phenotypes beyond laboratory settings and to test potential biomarkers in real-world settings, such as field and cohort studies, comparative effectiveness research, and large-scale pragmatic trials (Brietzke et al. 2019; Scott et al. 2019).

One of the domains identified by RDOC is the arousal and regulatory system, and RDOC suggests that sleepwake cycle and circadian rhythms (which we will refer to as rest-activity rhythms or RAR) represent a core construct for investigation (Insel 2014; Smagula 2016). This is of relevance to $\mathrm{BD}$, as converging evidence indicates that RAR disruptions can differentiate BD cases from healthy controls $(\mathrm{HC})$ and/or other comparator groups (Ritter et al. 2011; Geoffroy et al. 2015; Ng et al. 2015; De Crescenzo et al. 2017; Scott et al. 2017). Further, real-time monitoring of most of these phenomena may be possible with wrist-worn devices. Of course, there has been an exponential increase in the development and use of consumer grade wearables (and smart phone apps) in clinical populations (Faurolt-Jepson et al. 2012; Krane-Gartiser et al. 2019). However, many demonstrate low interdevice reliability, none of the apps or programmes are currently validated against 'gold standard' measures and few can accurately estimate key markers of circadian timing (Zee et al. 2014; FDA 2019; Depner et al. 2020). The lack of regulatory approval and absence of basic research on or rigour of testing their performance quality means consumer devices are not currently recommended for use in this research field (Baron 2018; FDA 2019; Moar 2018). Currently, RDOC indicates that actigraphy could be applied as an 'analytic unit' for longitudinal studies of circadian rhythms and sleep-wake cycles (Cuthbert 2014). Such studies are now underway, but there is no consensus regarding the most useful actigraphy-derived RAR parameters to estimate and/or report (Scott et al. 2019; Smagula 2016. Also, a preliminary scoping exercise of this topic suggested that relatively few actigraphy studies have employed a longitudinal or prospective design in BD. Therefore, we decided to collate any existing publications on these issues and synthesise the current state of knowledge.

This paper has three aims:

(a) To determine the number and type of actigraphy studies of samples comprised wholly or partly of individuals with $\mathrm{BD}$ that explore data regarding: outcome over time (e.g. relapse/recurrence according to polarity, or recovery/remission), treatment response or illness trajectories.

(b) To examine the range of actigraphy metrics that can be used to estimate disruptions of RAR and describe which individual circadian rhythm or sleep-wake cycle parameters are most consistently associated with outcome over time in BD.

(c) To demonstrate the use of evidence mapping as a process for synthesising the state-of-the-art in the field of ecological monitoring of RAR and disease modifiers, course of illness, treatment response or outcome in BD.

\section{Methods}

As the use of evidence-mapping dictates the structure of the paper, we provide a brief overview of this approach in Table 1. Below, we outline the application to the project described in this article.

\section{Rationale for use of mapping}

As noted in the introduction, the goal of this evidence map is to present an overview of the extent, range, nature, and findings of clinical research on RAR metrics measured by actigraphy and a range of potential outcomes of $\mathrm{BD}$. Like many evidence maps, the rationale for using this process was determined by prior knowledge of the field. Many research groups, including our own, have synthesized research findings or undertaken meta-analyses of 


\title{
Table 1 Brief overview of evidence mapping
}

\begin{abstract}
Evidence Mapping
Evidence mapping is defined as-

"a form of knowledge synthesis that addresses an exploratory research question aimed at mapping key concepts, types of evidence, and gaps in research related to a defined area or field by systematically searching, selecting, and synthesizing existing understanding"

The gold standard methods used in evidence-based research are systematic review and meta-analysis. These classic approaches are both rigorous and provide readers with detailed information about narrow questions (e.g. the efficacy of drug X for disorder $Y$ ). However, developments from this archetypal model are now being developed to meet more diverse needs regarding evidence synthesis (Arksey 2003 ; Miake-Lye et al. 2016). The obvious example is the use of rapid reviews (which address urgent topics and do not always fully adhere to systematic methodologies) or scoping reviews (that identify extensive bodies of literature but do not usually provide detailed synthesis) (Colquhoun et al. 2014). In this context, evidence mapping has emerged as another process that allows researchers and their audience to develop an understanding of the extent and distribution of evidence in on a broad topic, highlighting what is known and also where gaps exist (Katz et al. 2003; Hetrick et al. 2010). Although it applies systematic and replicable methodology, the process is iterative, as expert consensus and preliminary literature searches inform the next steps in the review, so the final product is broader and less detailed than the traditional approaches (Vallarino et al. 2015). Furthermore, the goal is not to provide detailed statistical comparisons, but rather to offer an essential snapshot of what is or is not known at this moment in time. It is presumed that an evidence map for any given field will be followed up in the future when research develops to a point where it becomes justifiable to apply more formal reviews and pooled analyses

The depth of evidence synthesized will differ depending on its purpose of an evidence map e.g. an overview of the extent, range and nature of research activity might entirely exclude any details of study findings (Miake-Lye et al. 2016). However, if the latter are considered, they can be represented by graphs and figures, instead of or as well as a detailed table such as the summary tables provided in systematic reviews (Hetrick et al. 2010)

Given the proposed scope of this map, we determined that a simple written summary with basic tables and figures would be offered in the results section of the paper. A detailed Table summarizing sample characteristics and research findings (in an Appendix) and citations in the reference list only would ensure readers focused on key findings we summarize. Individual readers could then choose to examine supporting evidence and relevant references for themes that they wished to investigate further
\end{abstract}

pooled data regarding $\mathrm{BD}$ cases compared with $\mathrm{HC}$ or other (comparator) groups (Ritter et al. 2011; Geoffroy et al. 2015). Some of those projects identified small-scale studies that used real-time monitoring of BD cases and/ or that examined associations between baseline actigraphy recordings and longitudinal course and outcome of BD (Scott et al. 2017). Nearly all of those projects were undertaken several decades ago and differences in sampling, diagnosis or research methods meant the publications failed to meet eligibility criteria for systematic reviews focused on a specific research question (De Crescenzo et al. 2017). Further, it was known that most of the reported data were insufficient (in terms of amount or quality) to merit inclusion in meta-analyses $(\mathrm{Ng}$ et al. 2015). As such, an evidence map offered a realistic option to gain an understanding of existing research in this area, especially capturing insights from multiple small-scale studies and mapping provides a means of summarizing the range of publications and findings in a transparent way (Vallarino et al. 2015). The potential advantage over a basic narrative or selective review is that the search process is reproducible, and the map specifically addresses gaps in the knowledgebase (Hetrick et al. 2010). However, findings are described in brief, so a map does not aim to offer the detailed lists of citations and extensive tables included in systematic reviews or meta-analyses.

\section{Mapping process}

The process usually incorporates four steps (clarifying focus; describing boundaries and 'coordinates' for mapping; literature search; charting the output maps). After consultation among the co-authors, the questions and scope of the mapping project were defined as follows-

\section{Step 1: Clarification of the focus of the map.}

It was agreed that the focus would be:

(a) What evidence exists on this topic and based on a review of study characteristics and methodologies: what conclusions can be drawn about the quality of evidence?

(b) What areas are, or are not, well-researched?

(c) Based on the available evidence, what advice can be offered to clinicians and investigators in the field?

Step 2: Description of the eligibility criteria (boundaries for inclusion and exclusion), specification of co-ordinates to be mapped (study characteristics associated with outcome/response, etc.) and definition of key variables (RAR metrics):

(a) Studies were eligible if:

Inclusion criteria-

i) The sample or cohort was wholly or partly comprised of $\mathrm{BD}$ cases that met clinical or research diagnostic criteria

ii) It reported associations between any RAR actigraphy metric recorded at baseline and a clinical or researchdefined outcome assessed at follow-up in BD cases (or vice versa). Note: For the purposes of the map, the focus was on BD cases, so we extracted informa- 
tion on inter-individual or intra-individual changes in actigraphy or outcomes in the clinical cases (i.e. we aimed to avoid focusing on findings of case-control studies or cross-sectional comparisons of RAR metrics between $\mathrm{BD}$ and $\mathrm{HC}$, which have been reviewed many times before).

iii) The publication reported any association between RAR metrics recorded by actigraphy and the outcome or response of $\mathrm{BD}$ in the short or long term (this could include e.g. naturalistic observational studies of treatment interventions and/or randomized controlled trials).

iv) Presence of comorbidities was not an exclusion criterion, but details were noted.

v) Findings from self-report questionnaires, consumer grade wearables or smartphone apps were eligible if the study also reported data for actigraphy recordings and/or the RAR findings extracted from questionnaires or wearables were reported alongside the equivalent metric derived from actigraphy.

\section{Exclusion criteria-}

The map aimed to capture the extent of the existing literature, so there were minimal exclusion criteria. The most significant criterion was that studies that failed to report any measures (quantity and/or or timing) of daytime activity were ineligible. Also excluded were single case reports or studies where the recruitment of participants was not based on a current diagnosis of BD or depression (UP and BD) e.g. studies of individuals at risk of $\mathrm{BD}$ or of individuals attending medical clinics (actigraphy has been used to assess treatment outcome in CVD and cancer).

(b) Study Coordinates.

It was agreed that the following would be mapped: year and geographic location of study (we also noted if the study specified seasonality, etc.); sample characteristics (demographics; diagnoses e.g. BD subtypes, inclusion of UP and BD; phase of illness at recruitment); community or clinical setting (e.g. in- or outpatient); duration of study; duration of actigraphy recording; and outcomes reported. The latter could include: outcome prediction; response to introduction of treatment or treatment withdrawal; acute or long-term treatment effects; longitudinal course of BD (continuous or repeated cross-sectional assessment) in terms of illness progression (naturalist follow-up or associated with treatment introduction or withdrawal), symptom exacerbation, relapse/recurrence/ recovery/remission and/or putative disease course modifiers (as defined in a study). Also eligible were: naturalistic observational studies in clinician settings (unspecified/ uncontrolled treatment), naturalistic monitoring of illness with unspecified/uncontrolled treatment and/or randomized controlled trials that incorporated actigraphy (if not identified via previous criteria).

(c) Definitions of Rest-Activity Rhythms.

It is clear from actigraphy studies in BD that the metrics reported have differed by location (i.e. geography) and decade of study. However, researchers have repeatedly acknowledged the close connection between sleep and circadian structure and that actigraphy data can be used for 'rhythmometric analysis' of RAR (Calogiuri et al. 2013; Smagula, 2016; Wirz-Justice, 2007). As such, all the metrics listed in Table 2 are considered as potentially relevant RAR markers in this project.

Table 2 gives an overview of the key RAR metrics that have been derived from actigraphy recordings in psychiatry (definitions and descriptions of each metric are provided in Table 3 in Appendix) (Calogiuri et al. 2013; Ancoli-Israel et al. 2003). As shown, investigators have focused on different rhythmometric procedures, which need to be considered when interpreting the map. For instance, early studies were likely to report parametric statistics (especially in the USA) (Nelson et al. 1979). Three variables (mesor, acrophase and amplitude) were estimated using cosinor methods (with the $p$ value

Table 2 Potential measures of rest-activity rhythms (further details are given in Appendix)

\begin{tabular}{|c|c|c|c|}
\hline Parametric (Cosinor) Model & $\begin{array}{l}\text { Non-parametric } \\
\text { Model }\end{array}$ & $\begin{array}{l}\text { Sleep Quantity Analysis Model } \\
\text { (Mean or Variability) }\end{array}$ & $\begin{array}{l}\text { Sleep Analysis- Circadian } \\
\text { Phase Model }\end{array}$ \\
\hline $\begin{array}{l}\text { Midline estimating statistic of } \\
\text { rhythm (MESOR) }\end{array}$ & Inter-daily Stability (IS) & Mean Activity (MA) & Sleep Onset \\
\hline Amplitude & Intra-daily Variability (IV) & Time in Bed (TIB) ( \pm Lights Off) & Sleep Offset \\
\hline \multirow[t]{5}{*}{ Acrophase } & Least active period: L5/ L5 Onset & Total Sleep Time (TST) & Sleep Midpoint \\
\hline & Most active period:M10/M10 Onset & Sleep Onset Latency (SOL) & Sleep Regularity Index (SRI) \\
\hline & Amplitude & Sleep Efficiency (SE \%) & \\
\hline & Relative Amplitude & Fragmentation Index (FI \%) & \\
\hline & & $\begin{array}{l}\text { Wake after sleep onset (WASO) }( \pm \mathrm{N} \\
\text { awakenings }>5 \mathrm{~min})\end{array}$ & \\
\hline
\end{tabular}


signifying the probability that the data really show circadian periodicity), whilst more recently these metrics have been derived using regression techniques (which report similar variables but assume more complex patterns and rhythms and are more robust for larger study populations) (Fernandez and Hermida 1998). Non-parametric methods report a wider range of variables to describe the quantity and timing of activity and rest, and especially provide insights into variability/stability of rhythms and any RAR disruptions (Calogiuri et al. 2013; Natale et al. 2009). They are often preferred to parametric models and it is argued that non-parametric models better represent the complexity of RAR than cosinor models (van Someren et al. 1997). Variables derived from basic sleep analysis (such as total sleep time: TST) are probably the most widely reported measures in research in BD. One reason for this is that these sleep quantity are much easier to estimate from raw data (and do not rely on more complex algorithms). Sleep variables are useful for estimating duration and fragmentation of sleep patterns but are less reflective of circadian rhythmicity. Estimation of variability in values for each sleep parameter is encouraged in contemporary literature on RAR and greater reporting of sleep onset/offset/midpoint or sleep regularity index has been employed to give a greater insight into rhythmometrics (Bei et al. 2016).

\section{Step 3: Literature Search}

The search approach was the same as utilized in systematic reviews. Search terms were applied to PubMed, MEDLINE, PsycINFO, EMBASE, CINAHL and Web of Science databases No limits were set for language, type of study or date of publication (the original telemetric motion sensors and actometers were used in BD in the early 1970s). The search terms included the full range of RAR metrics and potential outcomes listed in Step 2, supplemented by searches using names of medications (e.g. lithium, carbamazepine) or for research groups known to have contributed publications when this topic initially emerged in the literature. This approach was used to ensure the broadest possible range of publications were identified. Furthermore, hand-searches were undertaken of all reference lists of studies noted in narrative reviews, systematic reviews, and meta- analyses on this or similar topics. The final list of eligible studies was generated based on broad relevance to the scope of this map. Key drivers of selection of publications were that:

a) The study reported the use of an actigraphy device to undertake daytime or 24-h monitoring of RAR in BD

b) The study endpoint was described in terms of a recognizable clinical outcome or measure of response or change in RAR (if combined with baseline or followup clinical measures).

\section{Step 4. Charting: screening and positioning the relevant evidence within the map}

Based on the specified aims of the study, we agreed three core outputs:

a) Nature \& quality of research: a Table of study coordinates was planned. Co-authors would review the Table independently and produce a brief written synopsis of the key characteristics of the available research. This information was used to formulate a consensus on the nature and quality of the extant literature.

b) Extent of research: two maps would be generated. The first would describe year and country of study to provide a snapshot of research in this field by geography and over time. The second map would give an overview of the most common methodologies and research themes. These would be identified by extracting information regarding study coordinates and coding each of these separately, e.g. setting (e.g. inpatient); type (e.g. naturalistic observational; treatment outcome; response criteria; etc.); reported interventions (e.g. proportion of individuals taking lithium; numbers allocated to psychological intervention); whether interventions were compared (e.g. lithium versus quetiapine). These data could be combined to show the overall pattern of research.

c) A map would be generated to identify the range of RAR parameters reported across all studies and which individual metrics appeared to be consistently found to be associated with course and outcome of BD. Such a map can offer a heuristic framework and be the starting point for a systematic review or metaanalysis at a future date.

\section{Results}

Twenty-seven independent studies (reported in 29 publications) were included in the map. Table 4 in Appendix gives an overview of the studies and the core characteristics. To maintain the simplicity expounded in evidence mapping we have not included all the citations after every statement (the citations are in the reference list and the key studies can be easily identified from Table 3 ).

In the studies in the evidence map, the median age of all participants was 45 years and $60 \%$ were female. The median sample size was 15 per study (range: 2-75); 484 individuals with BD (out of a total of 560) participated in actigraphy and the median duration of recordings was 
7 days (range 1-210). Studies before 1990 tended to be smaller, but sample size did not appear to be determined by decade of publication, with several small-scale projects or BD subsamples (included in larger samples or cohorts) being followed-up longitudinally in recent studies. Overall, 17 studies comprised wholly or partly of inpatients (63\%). Two studies reported daytime activity monitoring only, one study used actigraphy primarily to confirm reported patterns of hypersomnia whilst a RCT examined changes in objective levels of morning activity following a psychological intervention targeted at sleep inertia.

There was evidence that statistical analyses of RAR have become more sophisticated over time, but earlier studies were more likely to address directly the association between RAR and phase of BD (e.g. transitions between mania, and depression), and change in RAR following initiation or withdrawal of treatment (especially lithium) (e.g. Kripke et al. 1979; Wolff et al. 1985). The sampling, design, and analytic strategies of most studies demonstrate several methodological flaws (e.g. repeated testing of small samples with correction, absence of reporting of non-significant outcomes). Overall, the consensus judged the quality of the studies to be modest.

Figure 1 shows that $>50 \%$ studies (14 of 27) were undertaken in the USA and it is only in the last decade that the number of studies undertaken across Europe has matched the USA. The earliest studies reported the seminal work undertaken by Kupfer and associates and pursued by researchers at NIMH; more recent studies represent projects exploring RAR as disease course modifiers or examining RAR as potential predictors of treatment response and/or to monitor treatment outcomes. Table 3 also demonstrates that there were no studies (meeting our eligibility criteria) that reported RAR in BD for more than a decade (1994-2006). This is most likely a consequence of the fact that psychiatry research shifted towards the reporting of metrics favoured by experts in sleep/sleep disorders, rather than focusing on metrics

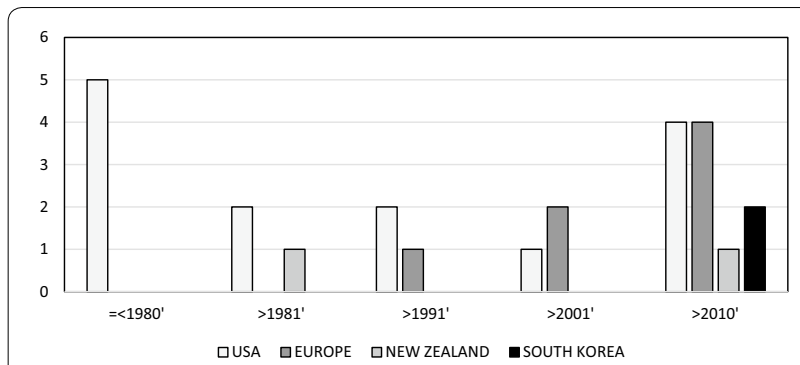

Fig. 1 Location of study \& decade of publication (Total =27). (Note: if $>1$ publication was identified relating to a dataset from a particular location, we included the date of the first publication only) most relevant to specific psychiatric disorders. Reviewing publications after 2006 suggests this this trend started to reverse when $\mathrm{BD}$ researchers increased their focus on sleep-wake cycles and also with the rise in interest in precision diagnostics and therapeutics.

As shown in Fig. 2, only 22\% studies reported follow-up assessments at $>6$ months $(\mathrm{N}=6)$. Naturalistic observational studies and treatment outcome studies are equally common $(\mathrm{N}=10 ; 37 \%)$. In nine studies, $>50 \%$ of the sample were taking lithium or the study specifically explored RAR and lithium treatment.

Although our preliminary work for the evidence-map identified $>30$ possible RAR parameters (parametric and non-parametric measures; mean or variable measures of sleep analysis; putative circadian phase markers extracted from sleep quantity analysis), the eligible studies only consistently reported estimates for seven metrics (see Fig. 3). Early studies mainly reported cosinor metrics (amplitude, acrophase and mesor), whilst the more recent studies increasingly report all raw data (either in the main text of the study or Appendices). However, in the middle decades, there was a tendency to only report statistically significant findings, without any indication as to whether other parameters were measured and/or which were found to be non-significant. Interestingly, when number of studies measuring a parameter is compared with the likelihood that a statistically significant association would be found, five variables were associated with outcome in $>50 \%$ of the studies. Namely: Variability/Rigidity of RAR (4 out of 4), $24 \mathrm{~h}$ rest activity cycle (22 out of 25 ), amplitude (5 out of 6 ), acrophase/phase advance (5 out of 7 ), and sleep efficiency (SE: 5 out of 8). In contrast, most measures of sleep quantity show weaker links: wake after

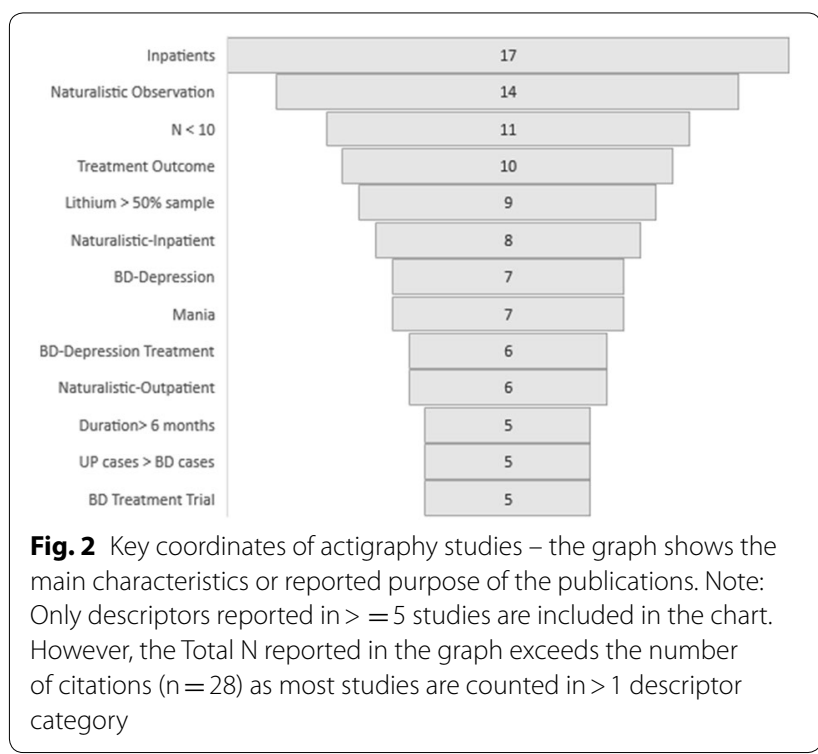




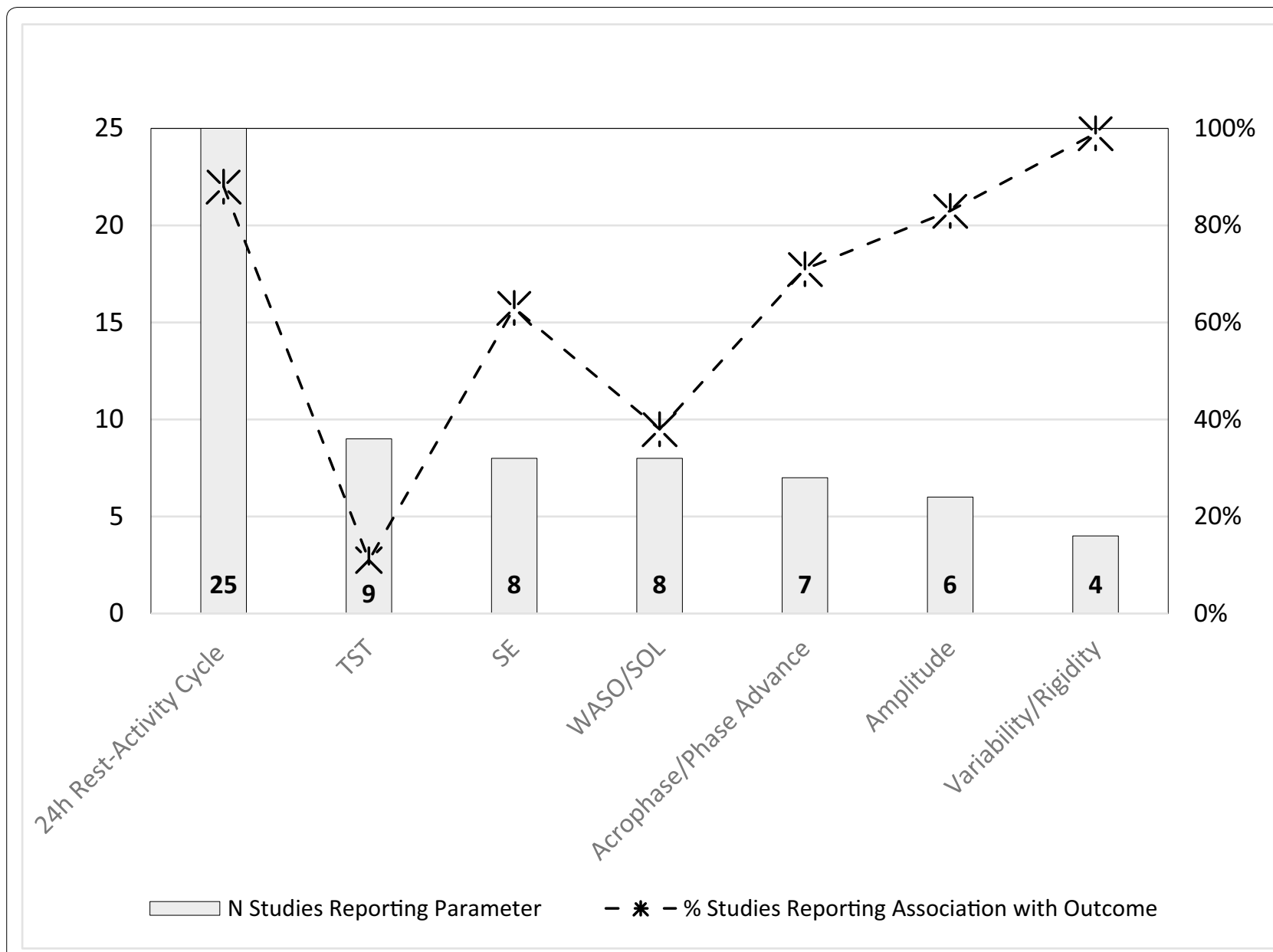

Key-SE: Sleep efficiency; SOL: Sleep onset latency; TST: Total sleep time; WASO: Wake after sleep onset

Fig. 3 Comparison of number of studies reporting each actigraphy metric \& proportion of those studies (\%) in which the parameter shows a significant association with an outcome of interest

sleep onset and sleep onset latency (WASO/SOL: 3 out of 8 ) and TST (1 out of 9 ) being the only metrics showing any significant associations.

It was not possible to provide specific evidence of the nature of the metrics that were most useful in different types of studies, although there was some trend of interest. Using information précised in Table 3, available evidence largely supports the view that mania is associated with circadian phase advance and BD-depression with phase delay. The latter was not obvious in studies of mixed samples of UP and BD depression. Interestingly, treatment may be associated with phase change, and treatments may have different effects on phase in BD-II, and phase shifts may can be associated with outcome at follow-up. The variable $24 \mathrm{~h}$ rest-activity cycle represents a global estimate of RAR and its primary value to the map is that it confirms that RAR can be used to assess a range of clinical outcomes in BD. Amplitude appeared to be a useful marker of illness course and treatment response or outcome. It was noted that variability/rigidity of RAR was only estimated in four small samples $(\mathrm{Ns}=3,8,10$, 12). These studies reported extended continuous durations of actigraphy and found the metrics to be significant markers of longitudinal course (including admissions). 
However, the studies did not report sufficient raw data or basic analyses to allow further investigation or interpretation of the findings.

\section{Discussion}

This article explores associations between RAR metrics measured via actigraphy and course, outcome and/or treatment response in $\mathrm{BD}$. The project arose from three converging strands of work. First, a background scoping exercise undertaken for the H2020-funded consortium exploring a range of putative markers of lithium response phenotypes (including actigraphy) (Scott et al. 2019); second, scrutiny of RDOC publications that suggest undertaking longitudinal actigraphy to explore RAR phenotypes in BD (Insel 2014); and third, a study of circadian and sleep-wake cycles in lithium responders and non-responders (Scott et al. 2020). These projects provided us with sufficient insights into this research field and, alongside our prior knowledge, led us to conclude that the existing literature on RAR and course/outcome/ response was unlikely to be suitable for systematic review or meta-analysis. Furthermore, it appeared it would be counter-productive to use these classic evidence-based techniques as they would prematurely restrict the focus of our investigation to a specific or narrow question of what presently seems to be an imprecise research area. As such, it was agreed that utilizing evidence mapping might enable some synthesis of the diverse range of (predominantly small-scale) studies currently available.

Regarding our first question (what evidence exists and what conclusions can be drawn about the quality of evidence?). We conclude that limited evidence exists, but what is available indicates that a discrete number of RAR metrics are more consistently associated with transition between different phases of $\mathrm{BD}$ and/or may be predictive of longitudinal course of illness or treatment response. The metrics that show the most frequent associations represent markers of the amount, timing, or variability of RAR rather than the sleep quality metrics that are frequently targeted in contemporary studies of BD. However, these putative 'circadian' signals should be viewed in context, as there is evidence of selective reporting of both metrics and outcomes, thus increasing the likelihood of publication bias. Notably, the statistical associations reported derive from multiple small-scale studies that together included $<500$ individuals with $\mathrm{BD}$. In sum, the findings are of interest, encourage pursuit of research in this field, but clearly expose that the quality of evidence and available published studies is modest.

Next, the second question addressed what areas are, or are not, well-researched? Our findings about the extent, nature and quality of the research, indicate that the available publications demonstrate the diverse ways in which RAR can be studied in the context of BD, but that no single area has been targeted for a prolonged period of research. Notably, the early studies showed a keen interest in treatment response (or change in illness with treatment withdrawal), but these themes were not pursued to a definitive conclusion. However, this theme is now drawing interest again and two recent studies used actigraphy to explore RAR and acute treatment outcome, namely ketamine infusions for depression (albeit in sample with many more UP than BD cases) and inpatient treatment of mania (such as Blue Blocking Glasses) (Duncan et al. 2017; Henriksen et al. 2020). The map also highlights evidence that clinical depressive symptoms are associated with robustness of circadian rhythm (e.g. Hwang et al. 2017), whilst current RAR patterns may predict future mental state (Salvatore et al. 2008). Also, in a small inpatient sample, it was shown that RAR recorded by actigraphy were associated with clinical progress, whilst estimates made with a consumer wearable were not (Averill et al. 2019). This is a useful reminder that research grade devices are still more accurate than consumer grade device and apps (and so actigraphy is likely to continue to have a role in the immediate future). Importantly, individuals with BD are prepared to wear actiwatches and/or consumer devices for extended periods ( $>6$ months) and this, allied with new conceptualizations of and analytic approaches to of RAR (such as fractal activity as an indicator system adaptability and lagged data analyses, etc.), may lead to a greater understanding of the chronological sequence of change of RAR, mood, cognition and other cardinal features of BD (Knapen et al. 2020; Walker et al. 2020).

The final question asked, based on the available evidence, what are the potential ways forward for the field? We suggest that one important option would be to develop a consensus within research consortia or wider groups of clinicians and investigators regarding the most appropriate RAR metrics to include in future actigraphy studies of BD (Scott et al. 2017). It is particularly 
important that this dialogue focuses on metrics that offer insights into RAR in BD that will have the optimal clinical as well as research utility for this field. This should be prioritized over simply generating a list of RAR measures recommended for estimation or reporting of sleep or sleep-wake research in general (Sack et al. 2007). These discussions will necessarily consider any RAR metrics that may represent trait or state variables (e.g. there is emerging evidence that relative amplitude, amplitude, interdaily stability and intradaily variability may be markers of disease onset as well as disease progression) (Merikangas et al. 2019; Scott et al. 2020). Developing a consensus is perhaps the most important recommendation that arises from this mapping exercise, as without such a course of action there is a clear possibility that we will continue to lack the means to make detailed crossstudy comparisons of the metrics that would offer most promise as diagnostic or response biomarkers.

An obvious gap in the available literature is the lack of youth studies of actigraphy that take a longitudinal perspective. Given the interest in staging models and temperament, research on the transition between subthreshold conditions or at-risk mental states and the onset of full-threshold illness episodes would be welcome. In individuals with established BD, consideration should be given to RAR metrics that might be combined in multi-platform research of precision diagnostics and therapeutics (Scott et al. 2019). For instance, precision studies that focus on prediction of response to mood stabilizers such as lithium, and the identification of biosignatures (rather than single biomarkers) might consider giving priority to reporting RAR markers such as amplitude and variablility (given our mapping findings regarding emerging evidence for their importance). The mapping exercise demonstrated that actigraphy studies are viable in inpatient as well as outpatient settings, as such, wider consideration should be given to monitoring inpatient progress using objective measures such as actigraphy, with the option of continuation to post-discharge settings. Of course, longitudinal monitoring that allows early warning signs of relapse or recurrent is also feasible with this ecological measure (Bellivier et al. 2015; Ritter et al. 2011). The above steps would address some of the explicit aims outlined by RDOC publications but could be valuable for clinicians e.g. they might consider using electronic monitoring or including sleep diaries as part of the clinical assessment of BD. The latter could be scrutinized not only to identify mean sleep duration and timing but also variability between weekdays and weekends or large differences in duration of sleep onset/offset/ duration over 2-3 weeks.

Whilst consumer grade wearables and smart phone apps are attractive to many, it is important to remember that they all await regulatory approval for use as clinical devices (and commercial developments of longer battery life to avoid repeated need for charging). However, their use alongside actigraphy could be helpful, both to validate different measures of RAR that might be derived from consumer devices but also to facilitate ecological momentary assessment (EMA) research (Merikangas et al. 2019; Depner et al. 2020). Research in this area is ongoing and has the advantage of combining self-report ratings of events, cognition, energy, and mood states with objective RAR data (de Wild-Hartmann et al. 2013; Merikangas et al. 2019). However, these advances necessarily require researchers to work more closely alongside statisticians and computational data scientists as the optimal methods for analyzing and understanding links between RAR, symptoms and behaviours are more sophisticated (including non-linear dynamics, entropy) than the basic approaches that are most commonly used and/or the algorithms that are currently available. Assuming this dialogue can occur, combining these approaches would allow to comprehensive exploration of the course of illness, prediction of treatment response and a range of patient reported outcomes (Moskowitz and Young, 2006; Marino et al. 2013). For clinicians, actigraphy offers access to objective ecological monitoring that provides a far more reliable and valid measure of RAR than can be obtained by self-rating scales (Depner et al. 2020; Mulligan 2016). However, not all clinicians feel confident in extracting data and metrics from the devices and this is likely to mitigate against wider dissemination beyond specialist settings. Another advantage of actigraphy is that it is a more feasible option for routine clinical practice than putative 'omic' and brain scanning markers of treatment response or illness outcome as these are less available, more expensive and often concentrated in research settings (Gooley and Chua 2014). Also, if the focus is on RAR, then actigraphic monitoring would be easier to integrate into a clinical management and monitoring package than evaluation of other objective circadian markers e.g. measurement of dim light melatonin onset (DLMO) (Depner et al. 2020). 


\section{Conclusions}

Despite 50 years of research, and several papers identified by this evidence map being highly cited, use of actigraphy to assess RAR in longitudinal research and examination of these metrics and treatment response, course and outcome of BD is under-investigated. This is in marked contrast to the extensive literature on casecontrol or cross-sectional studies of actigraphy, especially typical sleep analysis metrics in BD, which are reported in independent studies, systematic reviews, meta-analyses and meta-regressions. The most obvious reason for this marked disparity in the amount of research undertaken using these different methodologies, is that case-control and cross-sectional studies are easier to undertake, usually involve much briefer time frames, and have lower resource requirements than longitudinal research. Also, it was notable that prospective studies identified in this evidence map were still predominantly shorter-term projects, often reporting outcomes over weeks rather than months.

This evidence map suggests that the existence of several often-quoted publications has probably led to an overestimation of the extent and robustness of existing evidence of longitudinal associations between RAR and treatment response, course, and outcome in BD. However, we are aware of promising emerging findings in this area (McCarthy et al. 2019; Scott et al. 2020) and there is tremendous potential for expanding this field of research to inform precision medicine projects in psychiatry. Further, there is a strong argument that, rather than actigraphy being replaced by consumer grade devices and apps, it may be more fruitful to establish frameworks for clinical and research projects that combine these approaches.

\section{Abbreviations}

BD: Bipolar disorders; CVD: Cardiovascular disease; d: Days; DALYs: Disability adjusted life years; DLMO: Dim light melatonin onset; EMA: Ecological momentary assessment; HC: Healthy controls; IS: Inter-daily stability; IV: Intra-daily variability; Li: Lithium; N: Number; NIMH: National Institute of Mental Health; RDOC: Research domain criteria; RAR: Rest activity rhythms; SD: Standard deviation; SE: Sleep efficiency; SOL: Sleep onset latency; TST: Total sleep time; UP: Unipolar; WASO: Wake after sleep onset; wks: Weeks; yrs: Years.

\section{Authors' contributions}

All authors identified the key questions and coordinates for the map. Scott collated papers for the evidence map, Etain and Scott created summary tables and charts. Scott, Etain and Colom created the first full draft of the manuscript. All authors read and approved the final manuscript.

\section{Funding}

FB is the Principal Investigator and all the authors are investigators on the R-LiNK (Response to Lithium Network) project. This project has received funding from the European Union Horizon 2020 research and innovation program ((EU.3.1.1. Understanding health, wellbeing and disease: Grant No 754907). BE received funding from: Institut National de la Santé et de la Recherche Médicale (INSERM - Research Protocol C0829), Assistance Publique des Hôpitaux de Paris (APHP - Research Protocol GAN12). FC received funding from: Spanish Ministry of Economy and Competitiveness, through a FIS (PI15/00588; PI19/00009), and the Secretaria d'Universitats i Recerca del Departament d'Economia i Coneixement de la Generalitat de Catalunya, Government of Catalonia (2017_SGR_134). AY received funding from: National Institute for Health Research (NIHR) Biomedical Research Centre at South London and Maudsley NHS Foundation Trust and King's College London. The views expressed are those of the authors and not necessarily those of the NHS, the $\mathrm{NIHR}$, or the Department of Health.

\section{Data availability statement}

Data sharing is not applicable to this article as no datasets were generated or analysed during the current study. All the data referred to in this manuscript are publicly available in the manuscripts describing the original studies.

\section{Ethics approval and consent to participate}

The authors assert that all procedures contributing to this work comply with the ethical standards of the relevant national and institutional committees on human experimentation and with the Helsinki Declaration of 1975, as revised in 2008 .

\section{Consent for publication \\ Not applicable.}

\section{Competing interests}

The authors report no financial affiliation or other relationship relevant to the subject matter of this article. JS is a Visiting Professor at Diderot University, Paris and an Honorary Professor at Kings College, London. AY declares paid lectures and advisory boards for the following companies with drugs used in affective and related disorders: AstraZeneca, Eli Lilly, Lundbeck, Sunovion, Servier, Livanova, and Janssen. He is a paid consultant to Johnson \& Johnson, is lead Investigator for Embolden Study (AstraZeneca), BCI Neuroplasticity study and a pharma sponsored Aripiprazole in Mania study. His institution has received funding for investigator-initiated studies from AstraZeneca, Eli Lilly, Linova, Lundbeck, Wyeth, and Janssen.

\section{Author details}

${ }^{1}$ Institute of Neuroscience, Newcastle University, Newcastle upon Tyne, UK. ${ }^{2}$ Centre for Affective Disorders, Department of Psychological Medicine, Institute of Psychiatry, Psychology \& Neuroscience, King's College London, London, UK. ${ }^{3}$ Université Paris Diderot, Sorbonne Paris Cité, UMR-S 1144, 75013 Paris, France. ${ }^{4}$ IMIM-Hospital del Mar-CIBERSAM, Barcelona, Catalonia, Spain.

${ }^{5}$ Universitat Autònoma de Barcelona Barcelona-Catalonia, Barcelona, Spain.

${ }^{6}$ Département de Psychiatrie Et de Médecine Addictologique, AP-HP, GH Saint-Louis - Lariboisière - F. Widal, 75475 Paris, France. ${ }^{7}$ Inserm U114475006, Paris, France. ${ }^{8}$ South London and Maudsley NHS Foundation Trust, Bethlem Royal Hospital, Kent, UK. 


\section{Appendix}

See Tables 3 and 4.

\section{Table 3 Parameters reported in studies of Rest-Activity Rhythms: additional details}

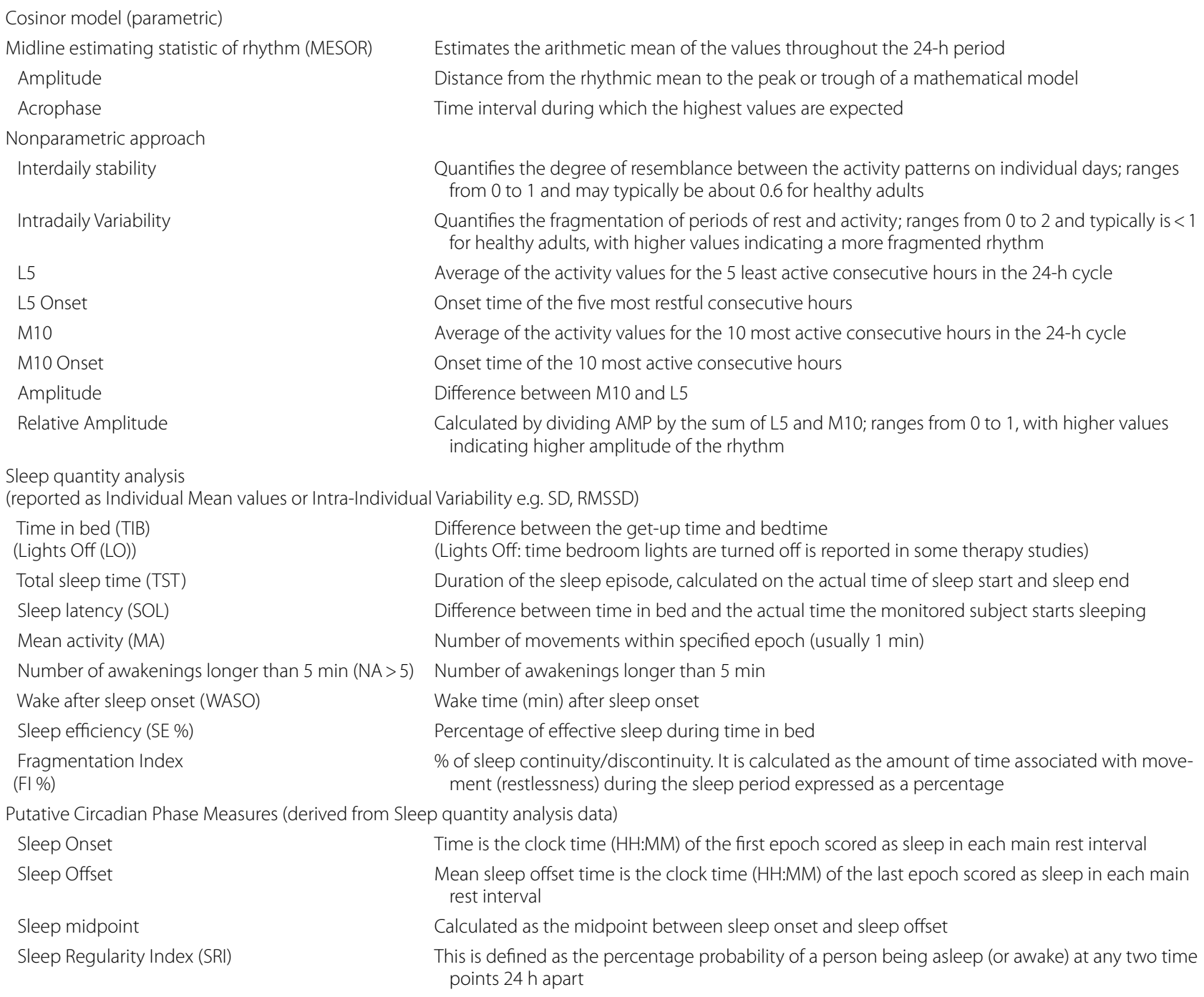

Cosinor model descriptions from Nelson et al (1979); nonparametric approach descriptions from Van Someren et al (1997). Sleep quantity analysis variables and descriptions as from Natale et al (2009), Krane-Gartiser et al. (2019) and Bei et al (2016)

IS quantifies regularity in activity (overall variability in a time-signal after averaging across days) \& IV quantifies fragmentation; some argue that SRI best quantifies how rapidly sleep patterns change between consecutive days 


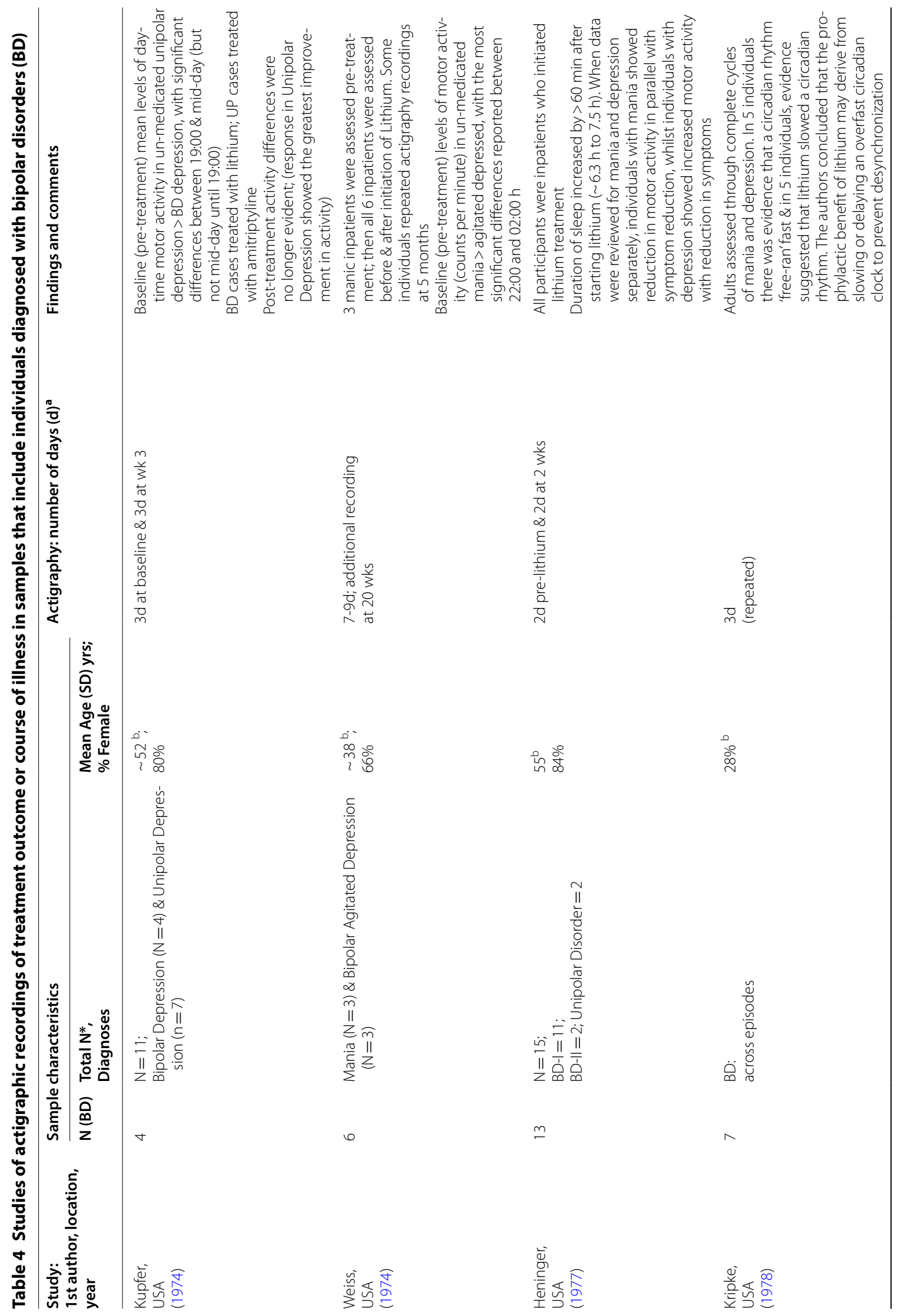




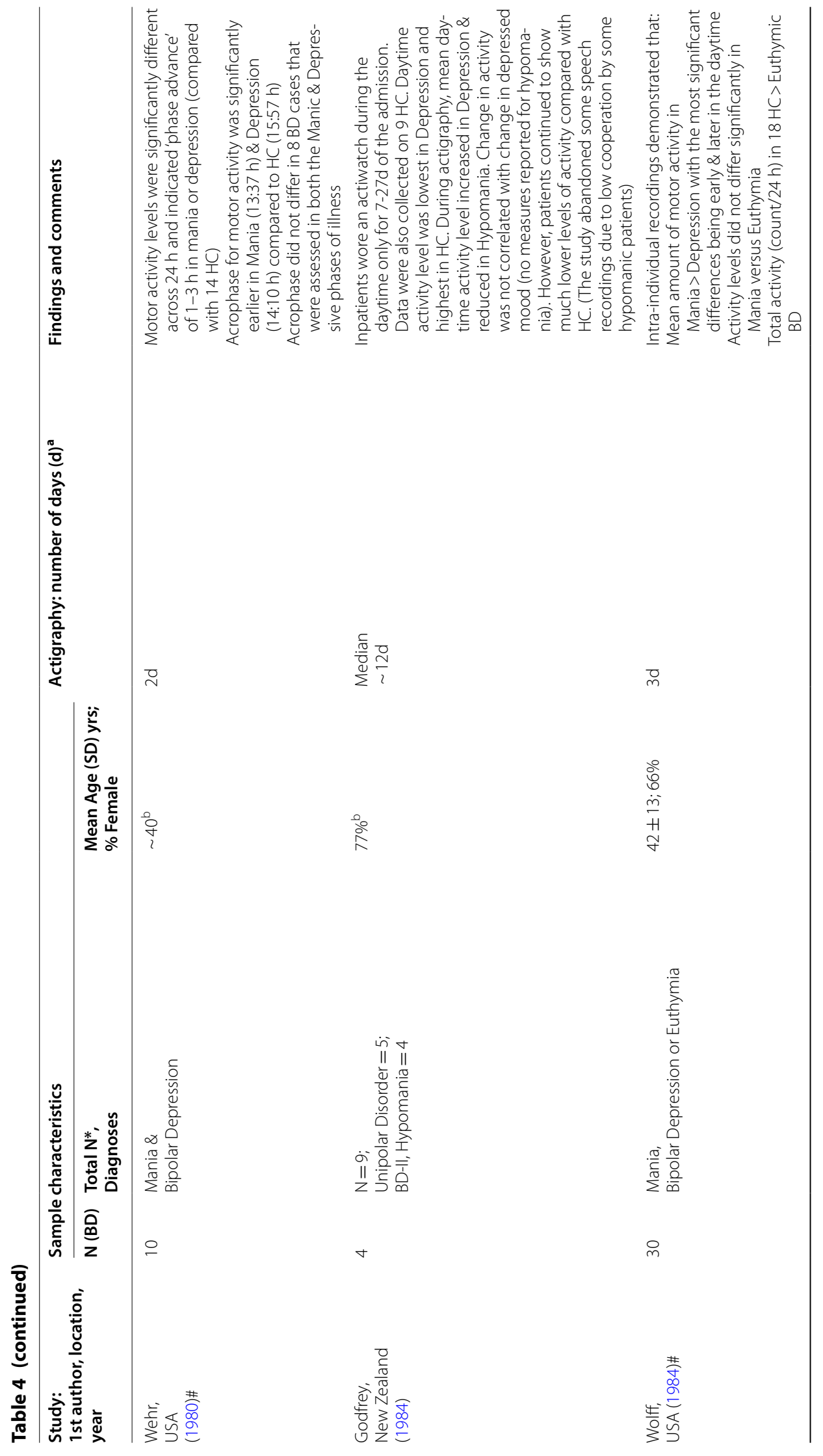




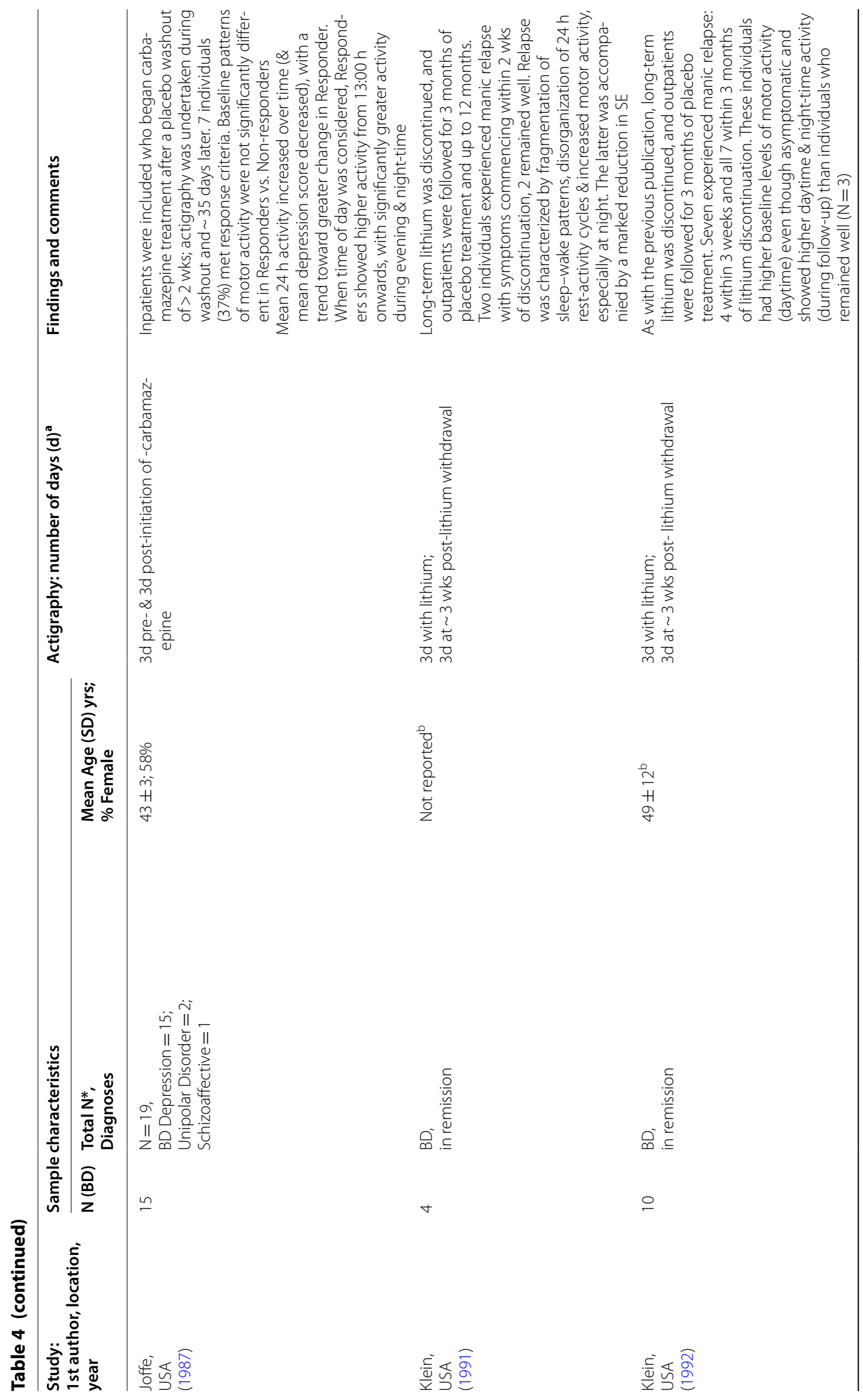




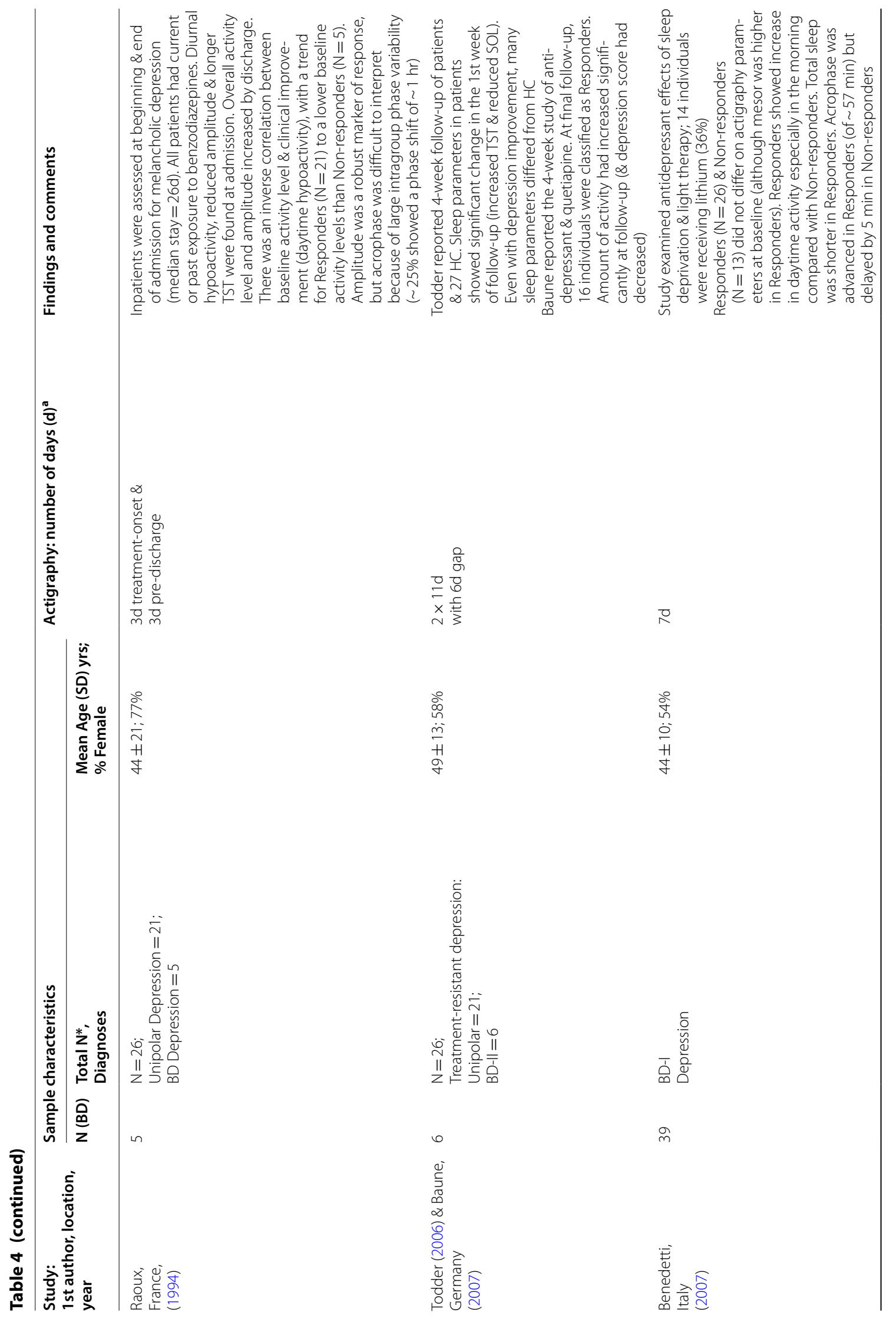




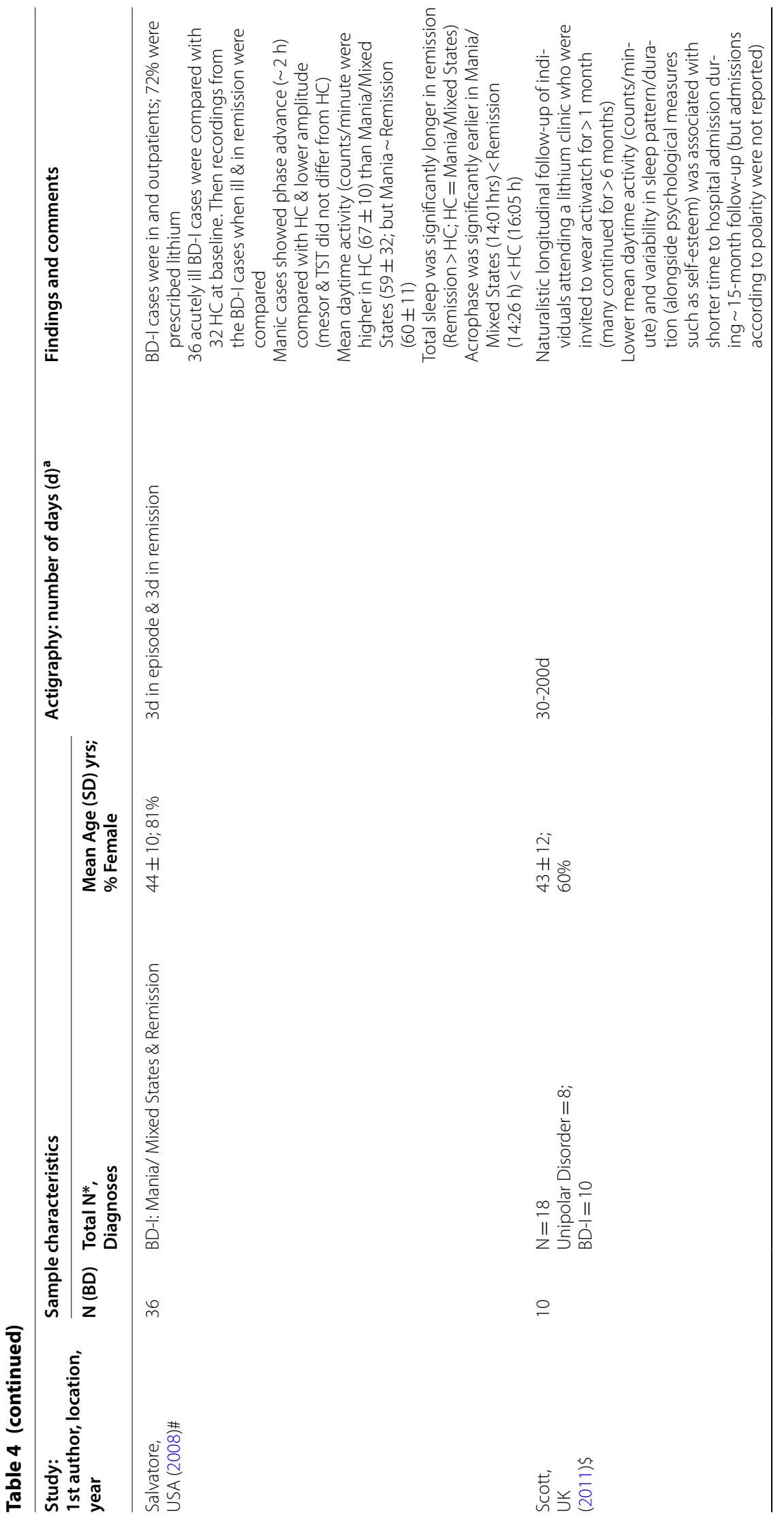




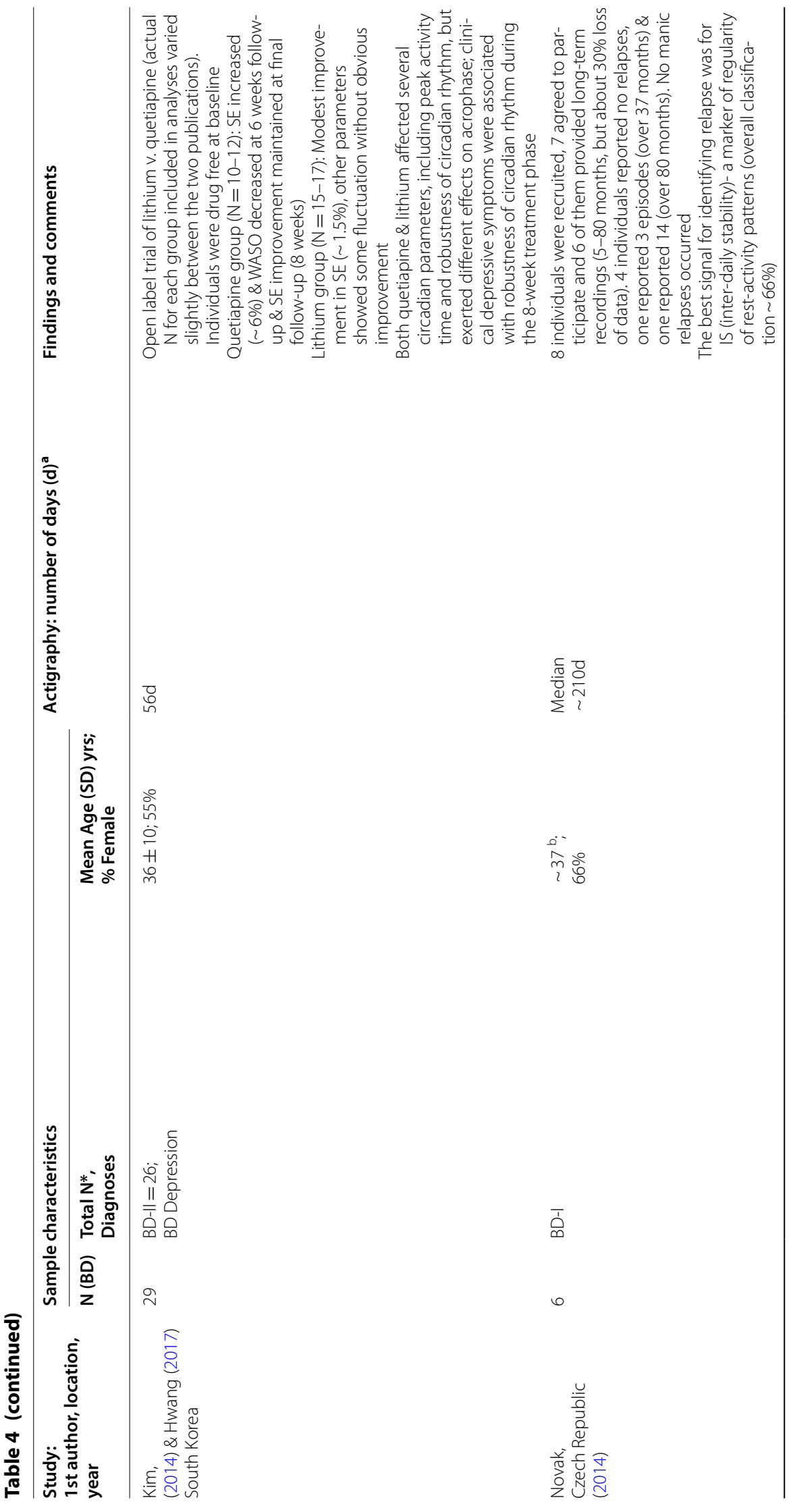




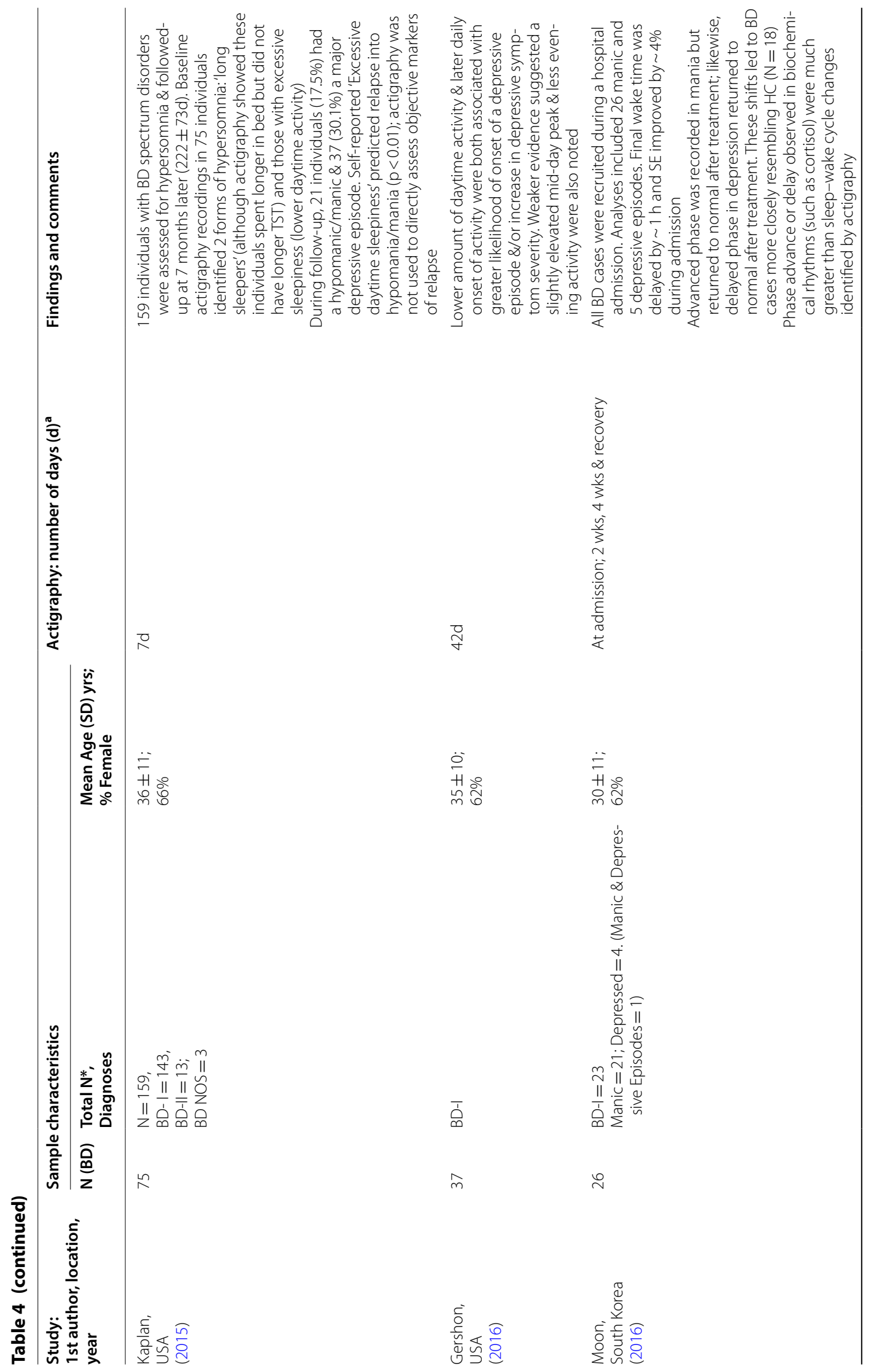




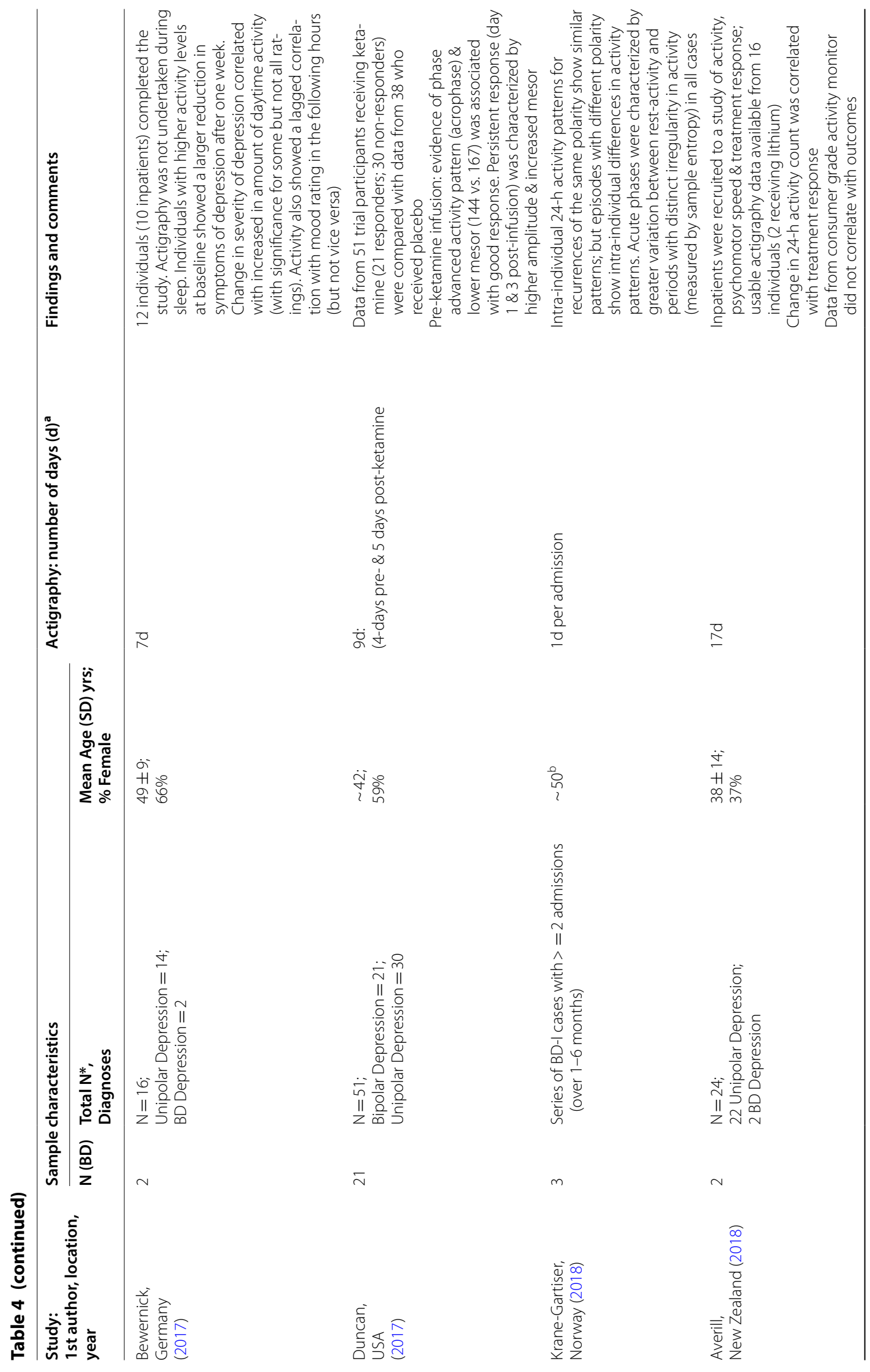




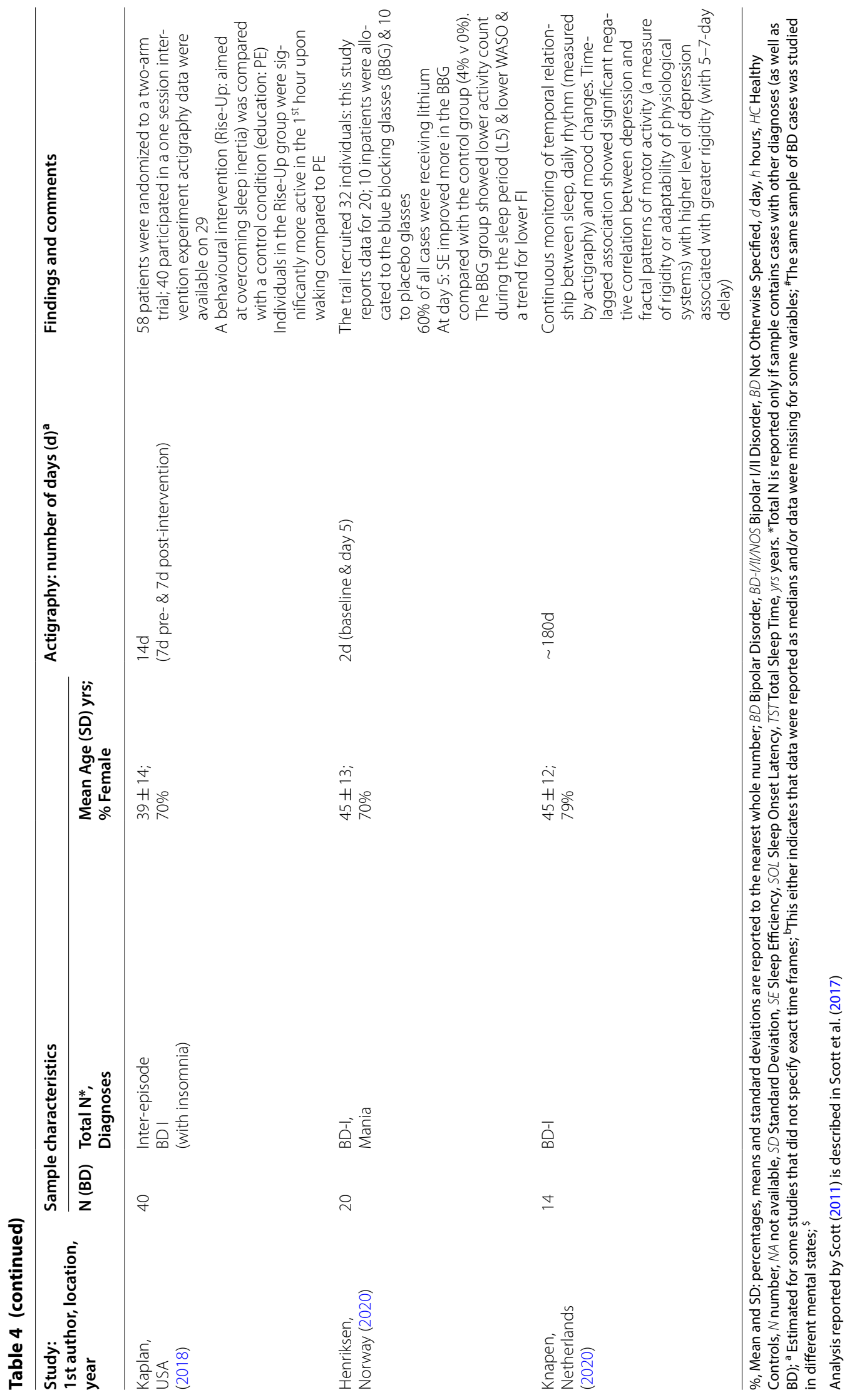


Received: 2 July 2020 Accepted: 25 August 2020

Published online: 01 December 2020

\section{References}

Ancoli-Israel S, Cole R, Alessi C, Chambers M, Moorcroft W, Pollak CP. The role of actigraphy in the study of sleep and circadian rhythms. Sleep. 2003;26(3):342-92.

Arksey $\mathrm{H}$. Scoping the field: services for carers of people with mental health problems. Health Soc Care Community. 2003;11(4):335-44.

Averill I, Beaglehole B, Douglas K, Crowe M, Inder M, Lacey L, et al. Activation therapy for the treatment of inpatients with depression - protocol for a randomised control trial compared to treatment as usual. BMC Psychiatry. 2019;19(1):52

Baron K. Feeling validated yet? A scoping review of the use of consumer-targeted wearable and mobile technology to measure and improve sleep. Sleep Med Rev. 2018;40:151-9.

Baune BT, Caliskan S, Todder D. Effects of adjunctive antidepressant therapy with quetiapine on clinical outcome, quality of sleep and daytime motor activity in patients with treatment-resistant depression. Hum Psychopharmacol. 2007;22(1):1-9.

Bei B, Wiley JF, Trinder J, Manber R. Beyond the mean: a systematic review on the correlates of daily intraindividual variability of sleep/wake patterns. Sleep Med Rev. 2016;2(8):108-24.

Bellivier F, Geoffroy P, Etain B, Scott J. Sleep-and circadian rhythm-associated pathways as therapeutic targets in bipolar disorder. Expert Opin Ther Targets. 2015;19:747-63.

Benedetti F, Dallaspezia S, Fulgosi MC, Barbini B, Colombo C, Smeraldi E. Phase advance is an actimetric correlate of antidepressant response to sleep deprivation and light therapy in bipolar depression. Chronobiol Int. 2007;24(5):921-37.

Bewernick BH, Urbach AS, Bröder A, Kayser S, Schlaepfer TE. Walking away from depression-motor activity increases ratings of mood and incentive drive in patients with major depression. Psychiatry Res. 2017;247:68-72.

Brietzke E, Hawken ER, Idzikowski M, Pong J, Kennedy SH, Soares CN. Integrating digital phenotyping in clinical characterization of individuals with mood disorders. Neurosci Biobehav Rev. 2019;104:223-30.

Calogiuri G, Weydahl A, Carandente F. Methodological issues for studying the rest-activity cycle and sleep disturbances: a chronobiological approach using actigraphy data. Biol Res Nurs. 2013;15(1):5-12.

Colquhoun H, Levac D, O'Brien K, Straus S, Tricco A, Perrier L, et al. Scoping reviews: time for clarity in definition, methods, and reporting. J Clin Epidemiol. 2014;67(12):1291-4.

Cuthbert BN. Translating intermediate phenotypes to psychopathology: the NIMH Research Domain Criteria. Psychophysiology. 2014;51(12):1205-6.

Cuthbert B, Insel T. Toward the future of psychiatric diagnosis: the seven pillars of RDoC. BMC Medicine. 2013;11:126.

De Crescenzo F, Economou A, Sharpley A, Gormez A, Quested D. Actigraphic features of bipolar disorder: a systematic review and meta-analysis. Sleep Med Rev. 2017;33:58-69.

Depner C, Cheng P, Devine J, Khosla S, de Zambotti M, Robillard R, Vakulin A, Drummond S. Wearable technologies for developing sleep and circadian biomarkers: a summary of workshop discussions. Sleep. 2020;43(2):254.

de Wild-Hartmann J, Wichers M, van Bemmel A, Derom C, Thiery E, Jacobs N, van Os J, Simons C. Day-to-day associations between subjective sleep and affect in regard to future depression in a female population-based sample. Br J Psychiatry. 2013;202:407-12.

Duncan W, Slonena E, Hejazi N, Brutsche N, Yu K, Park L, et al. Motor-activity markers of circadian timekeeping are related to ketamine's rapid antidepressant properties. Biol Psychiat. 2017;82(5):361-9.

Faurholt-Jepsen M, Brage S, Vinberg M, Christensen EM, Knorr U, Jensen HM, Kessing LV. Differences in psychomotor activity in patients suffering from unipolar and bipolar affective disorder in the remitted or mild/moderate depressive state. J Affect Disord. 2012;141(2-3):457-63.

Fernandez J, Hermida R. Inferential statistical method for analysis of non-sinusoidal hybrid time series with unequidistant observations. Chronobiol Int. 1998;15:191-204.

Food and Drug Administration (FDA). 2019. Digital Health Software Precertification (Pre-Cert) Program. https://www.fda.gov/medical-devices/ digital-health/digital-health-software-precertification-pre-cert-progr am). Accessed 20 May 2020.

Frey B, Andreazza AC, Houenou J, Jamain S, Goldstein B, Frye M, et al. Biomarkers in bipolar disorder: a positional paper from the International Society for Bipolar Disorders Biomarkers Task Force. Aust N Z J Psychiatry. Apr ;47(4):321-32.

GBD 2017 Disease and Injury Incidence and Prevalence Collaborators.Global, regional, and national incidence, prevalence, and years lived with disability for 354 diseases and injuries for 195 countries and territories, 1990-2017: a systematic analysis for the Global Burden of Disease Study 2017. The Lancet. 8 Nov 2018; 392:1789-858.

Geoffroy P, Scott J, Boudebesse C, Lajnef M, Henry C, Leboyer M, Bellivier F, Etain B. Sleep in patients with remitted bipolar disorders: a meta-analysis of actigraphy studies. Acta Psychiatr Scand. 2015;131(2):89-99.

Gershon A, Ram N, Johnson SL, Harvey AG, Zeitzer JM. Daily actigraphy profiles distinguish depressive and inter-episode states in bipolar disorder. Clin Psychol Sci. 2016;4(4):641-50.

Godfrey H, Knight R. The validity of actometer and speech activity measures in the assessment of depressed patients. Br J Psychiatry. 1984;145(2):159-63.

Gooley J, Chua E. Diurnal regulation of lipid metabolism and applications of circadian lipidomics. J Genet Genomics. 2014;41:231-50.

Hellwig S, Domschke K. Update on PET imaging biomarkers in the diagnosis of neuropsychiatric disorders. Curr Opin Neurol. 2019;32(4):539-47.

Heninger GR, Kirstein L. Effects of lithium carbonate on motor activity in mania and depression. J Nerv Ment Dis. 1977;164(3):168-75.

Henriksen T, Gronli J, Assmus J, Fasmer O, Schoeyen H, Leskauskaite I, et al. Blue-blocking glasses as additive treatment for mania: effects on actigraphy-derived sleep parameters. J Sleep Res. 2020;2020:e12984.

Hetrick S, Parker A, Callahan P, Purcell R. Evidence mapping: illustrating an emerging methodology to improve evidence-based practice in youth mental health. J Eval Clin Pract. 2010;16:1025-30.

Hwang JY, Choi JW, Kang SG, Hwang SH, Kim SJ, Lee YJ. Comparison of the effects of Quetiapine XR and lithium monotherapy on actigraphy-measured circadian parameters in patients with bipolar ii depression. J Clin Psychopharmacol. 2017;37(3):351-4.

Insel T. The NIMH Research Domain Criteria (RDoC) Project: precision medicine for psychiatry. Am J Psychiatry. 2014;171:395-7.

Joffe RT, Uhde TW, Post RM, Minichiello MD. Motor activity in depressed patients treated with carbamazepine. Biol Psychiatry. 1987;22(8):941-6.

Kaplan KA, McGlinchey EL, Soehner A, Gershon A, Talbot LS, Eidelman P, Gruber J, Harvey AG. Hypersomnia subtypes, sleep, and relapse in bipolar disorder. Psychol Med. 2015;45(8):1751-63.

Kaplan KA, Talavera DC, Harvey AG. Rise and shine: A treatment experiment testing a morning routine to decrease subjective sleep inertia in insomnia and bipolar disorder. Behav Res Ther. 2018;111:106-12.

Katz DL, Williams A, Girard C, Goodman J, Comerford B, Behrman A, Bracken M. The evidence base for complementary and alternative medicine: methods of evidence mapping with application to CAM. Altern Ther Health Med. 2003;9(4):22-30

Kim SJ, Lee YJ, Lee YJ, Cho SJ. Effect of quetiapine XR on depressive symptoms and sleep quality compared with lithium in patients with bipolar depression. J Affect Disord. 2014;157:33-40.

Klein E, Lavie P, Meiraz R, Sadeh A, Lenox RH. Increased motor activity and recurrent manic episodes: predictors of rapid relapse in remitted bipolar disorder patients after lithium discontinuation. Biol Psychiatry. 1992;31(3):279-84.

Klein E, Mairaz R, Pascal M, Hefez A, Lavie P. Discontinuation of lithium treatment in remitted bipolar patients: relationship between clinical outcome and changes in sleep-wake cycles. J Nerv Ment Dis. 1991;179(8):499-501.

Knapen S, Li P, Riemersma-van der Lek R, Verkooijen S, Boks M, Schoevers $\mathrm{R}$, Scheer F, Hu K. Fractal biomarker of activity in patients with bipolar disorder. Psychol Med. 2020: 1, 1-8.

Krane-Gartiser K, Scott J, Nevoret C, Benard V, Benizri C, Brochard H, et al. Which actigraphic variables optimally characterize the sleep-wake cycle of individuals with bipolar disorders? Acta Psychiatr Scand. 2019;139(3):269-79.

Kripke DF, Mullaney DJ, Atkinson M, Wolf S. Circadian rhythm disorders in manic-depressives. Biol Psychiat. 1978;13(3):335-51.

Kripke DF, Judd LL, Hubbard B, Janowsky DS, Huey LY. The effect of lithium carbonate on the circadian rhythm of sleep in normal human subjects. Biol Psychiatry. 1979;14(3):545-8. 
Kupfer D, Weiss B, Foster G, Detre T, McPartland R. Psychomotor activity in affective states. Arch Gen Psychiatry. 1974;30(6):765-8.

MacDonald K, Krishnan A, Cervenka E, Hu G, Guadagno E, Trakadis Y. Biomarkers for major depressive and bipolar disorders using metabolomics: a systematic review. Am J Med Genet B Neuropsychiatr Genet. 2019;180(2):122-37.

Marino M, Li Y, Rueschman M. Measuring sleep: accuracy, sensitivity, and specificity of wrist actigraphy compared to polysomnography. Sleep. 2013:36:1747-55.

McCarthy M, Wei H, Nievergelt C, Stautland A, Maihofer A, Welsh DK. Chronotype and cellular circadian rhythms predict the clinical response to lithium maintenance treatment in patients with bipolar disorder. Neuropsychopharmacology. 2019;44:620-8.

Merikangas KR, Swendsen J, Hickie IB, Cui L, Shou H, Merikangas A, et al. Real-time mobile monitoring of the dynamic associations among motor activity, energy, mood, and sleep in adults with bipolar disorder. JAMA Psychiatry. 2019;76(2):190-8.

Miake-Lye I, Hempel S, Shanman R. What is an evidence map? A systematic review of published evidence maps and their definitions, methods, and products. Syst Rev. 2016;5:28.

Moar J. Where Now for Wearables. 2018; https://www.juniperresearch.com/ document-library/white-papers/where-now-for-wearables. Accessed 20 May 2020.

Moon J, Cho C, Son G, Geum D, Chung S, Kim H, et al. Advanced circadian phase in mania and delayed circadian phase in mixed mania and depression returned to normal after treatment of bipolar disorder. EBioMedicine 2016;11:285-95.

Moskowitz D, Young S. Ecological momentary assessment: what it is and why it is a method of the future in clinical psychopharmacology. J Psychiatry Neurosci. 2006;31(1):13-20.

Mullington J. Developing biomarker arrays predicting sleep and circadiancoupled risks to health. Sleep. 2016;39(4):727-36.

Natale V, Plazzi G, Martoni M. Actigraphy in the assessment of insomnia: a quantitative approach. Sleep. 2009;32:767-71.

Nelson W, Tong Y, Lee J, Halberg F. Methods for cosinor rhythmometry. Chronobiologia. 1979;6:305-23.

Novak D, Albert F, Spaniel F. Analysis of actigraph parameters for relapse prediction in bipolar disorder: a feasibility study. Conf Proc IEEE Eng Med Biol Soc. 2014;2014:4972-5.

Ng T, Chung K, Ho F, Yeung W, Yung K, Lam T. Sleep-wake disturbance in interepisode bipolar disorder and high-risk individuals: a systematic review and meta-analysis. Sleep Med Rev. 2015:20:46-58.

Raoux N, Benoit O, Dantchev N. Circadian pattern of motor activity in major depressed patients undergoing antidepressant therapy: Relationship between actigraphic measures and clinical course. Psychiatry Res. 1994:52:85-98.

Ritter PS, Marx C, Bauer M, Leopold K, Pfennig A. The role of disturbed sleep in the early recognition of bipolar disorder: a systematic review. Bipolar Disord. 2011;13(4):437.

Sack R, Auckley D, Auger R, Carskadon M, Wright K, Vitiello M, Zhdanov I. Circadian rhythm sleep disorders: Part II, advanced sleep phase disorder delayed sleep phase disorder, free-running disorder, and irregular sleepwake rhythm. An American Academy of Sleep Medicine review. Sleep. 2007;30:1484-501.

Salvatore P, Ghidini S, Zita G, De Panfilis C, Lambertino S, Maggini C, Baldessarini R. Circadian activity rhythm abnormalities in ill and recovered bipolar I disorder patients. Bipolar Disord. 2008;10:256-65.

Schumann G, Binder E, Holte A, de Kloet E, Oedegaard K, Robbins T, et al. Stratified medicine for mental disorders. Eur Neuropsychopharmacol. 2014;24(1):5-50.

Scott J. Clinical parameters of circadian rhythms in affective disorders. Eur Neuropsychopharmacol. 2011;21(suppl 4):S671-5.

Scott J, Etain B, Bellivier F. Can an integrated science approach to precision medicine research improve lithium treatment in bipolar disorders? Front Psychiatry. 2018;9:360
Scott J, Hidalgo-Mazzei D, Strawbridge R, Young A, Resche-Rigon M, Etain $B$, et al. Prospective cohort study of early biosignatures of response to lithium in bipolar-I-disorders: overview of the H2020-funded R-LiNK initiative. Int J Bipolar Disord. 2019;7(1):20.

Scott J, Murray G, Henry C, Morken G, Scott E, Angst J, Merikangas KR, Hickie IB. Activation in bipolar disorders: a systematic review. JAMA Psychiatry. 2017:74(2):189-96.

Scott J, Hennion V, Meyrel M, Bellivier F, Etain B. (2020) An ecological study of objective rest-activity markers of lithium response in bipolar I disorder. Paper submitted.

Smagula SF. Opportunities for clinical applications of rest-activity rhythms in detecting and preventing mood disorders. Curr Opin Psychiatry. 2016;29(6):389-96.

Todder D, Caliskan S, Baune B. Night locomotor activity and quality of sleep in quetiapine-treated patients with depression. J Clin Psychopharmacol. 2006;26(6):638-42

Vallarino M, Henry C, Etain B, Gehue L, MacNeill C, Scott E, et al. An evidence map of psychosocial interventions for the earliest stages of bipolar disorder. Lancet Psychiatry. 2015;2(6):548-63.

van Someren E, Kessler A, Mirmiran M, Swaab D. Indirect bright light improves circadian rest-activity rhythm disturbances in demented patients. Biol Psychiat. 1997;41:955-63.

Walker W, Walton J, DeVries A, Nelson R. Circadian rhythm disruption and mental health. Transl Psychiatry. 2020;10(1):28.

Wirz-Justice A. How to measure circadian rhythms in humans. Medicographia. 2007;29:84-90.

Wehr T, Muscettola G, Goodwin F. Urinary 3-methoxy-4-hydroxyphenylglycol circadian rhythm. Early timing (phase-advance) in manic-depressives compared with normal subjects. Arch Gen Psychiatry. 1980 Mar;37(3):257-63.

Weiss B, Foster F, Reynolds C, Kupfer D. Psychomotor activity in mania. Arch Gen Psychiatry. 1974;31(3):379-83.

Whiteford HA, Degenhardt L, Rehm J, Baxter AJ, Ferrari AJ, Erskine HE, et al. Global burden of disease attributable to mental and substance use disorders: findings from the Global Burden of Disease Study 2010. Lancet. 2013:382:1575-86.

Wolff E, Putnam F, Post R. Motor activity and affective illness. The relationship of amplitude and temporal distribution to changes in affective state. Arch Gen Psychiatry. 1985;42(3):288-94.

Zee P, Badr M, Kushida C, Mullington J, Pack A, Parthasarathy S, et al. Strategic opportunities in sleep and circadian research: report of the Joint Task Force of the Sleep Research Society and American Academy of Sleep Medicine. Sleep. 2014;37(2):219-27.

\section{Publisher's Note}

Springer Nature remains neutral with regard to jurisdictional claims in published maps and institutional affiliations.

\section{Submit your manuscript to a SpringerOpen ${ }^{\circ}$ journal and benefit from:}

- Convenient online submission

- Rigorous peer review

- Open access: articles freely available online

- High visibility within the field

- Retaining the copyright to your article

Submit your next manuscript at springeropen.com 